\title{
Sexually transmitted infections: old foes on the rise
}

\author{
Didac Carmona-Gutierrez ${ }^{1,{ }^{*}}$, Katharina Kainz ${ }^{1}$ and Frank Madeo ${ }^{1,2,{ }^{*}}$ \\ ${ }^{1}$ Institute of Molecular Biosciences, NAWI Graz, University of Graz, Humboldtstr. 50, 8010 Graz, Austria. \\ ${ }^{2}$ BioTechMed-Graz, Humboldtstr. 50, 8010 Graz, Austria. \\ * Corresponding Authors: \\ Frank Madeo; E-mail: frank.madeo@uni-graz.at; \\ Didac Carmona-Gutierrez; E-mail: carmonag@uni-graz.at.
}

\begin{abstract}
Sexually transmitted infections (STIs) are commonly spread via sexual contact. It is estimated that one million STIs are acquired every day worldwide. Besides their impact on sexual, reproductive and neonatal health, they can cause disastrous and life-threatening complications if left untreated. In addition to this personal burden, STIs also represent a socioeconomic problem, deriving in treatment costs of tremendous proportions. Despite a substantial progress in diagnosis, treatment and prevention, the incidence of many common STIs is increasing, and STIs continue to represent a global public health problem and a major cause for morbidity and mortality. With this Special Issue, Microbial Cell provides an in-depth overview of the eight major STIs, covering all relevant features of each infection.
\end{abstract}

Sexually transmitted infections (STIS) are old acquaintances. For instance, references to the symptoms of gonorrhea, incidentally a term implemented by the Greek physician Galen in the second century [1], can be found in the Bible [1, 2]. In medieval times, for example, syphilis was one of the most ubiquitous STIs in Europe. Interestingly, at that time it was a rather novel infection for this continent: according to one hypothesis crew members of the first Columbian expeditions to the Americas might have been responsible for importing this STI and originating the first recorded epidemic of syphilis in Europe in 1495 [3, 4]. Indeed, given the fact that STIs are transmitted via the universal and unavoidable act that is sexual practice, their infectious potential is considerable and has remained a threat until the present day. While young adults (age 15-24) are at higher risk for acquiring an STI, the incidence in the older population (age $>50$ ) is growing due to limited sexual health services, increased longevity and the availability of sexual performance enhancement drugs [5, 6].

Despite public awareness, prevention strategies and medical advances, STIs continue to persist as a major public health problem. Although it seems that they have lost a lot of their terrifying character, STIs do continue to be an important cause of morbidity and mortality worldwide. For instance, the danger of a possible STI transmission makes unprotected sexual intercourse the second most important risk factor for disability and death in low-income nations and the ninth most important in more economically developed countries [7]. STIs have a major impact on sexual, reproductive and neonatal health and - if left untreated - may cause disastrous and even life-threatening complications: pelvic inflammatory disease, infertility, cervical cancer, ectopic pregnancy, miscarriage, fetal death, or congenital infections are only some of the common side effects associated with diverse STIs [8, 9]. Notably, there might exist infection synergies individuals who are positive for one between different STIs $[8,9]$. This has been most extensively studied for the human immunodeficiency virus (HIV) with a number of biological mechanisms having been suggested to account for such

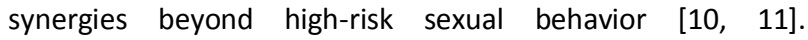
Importantly, patients frequently have to cope not only with their physical afflictions but also with the social and psychological consequences of having an STI. Even in the 21st century, STIs are usually viewed as shameful diseases, and affected individuals are still stigmatized and often enough socially condemned. Hence, suffering from an STI can impact people in nearly all parts of their daily life.

STIs are a problem that impacts society beyond the individual realm, representing a huge economic burden for healthcare systems. For instance, the Centers for Disease Control and Prevention (CDC) estimate the number of new STI cases at about 20 million per year in the US and calculate that the costs for the US healthcare systems to treat the eight most common STIs amount to a total of approximately $\$ 16$ billion US dollars each year [12]. It should be noted that this computation also includes lifelong treatment in terms of incurable STIs (e.g. HIV) and therapy costs for STI-related disorders (e.g. HPV-related cancer). Still, the treatment expenses of curable STIs add up to about $\$ 740$ million per year [12]. Taking all aspects together, prevention is indeed better than cure. Precluding transmission is thus the key approach to counteract these infections, as outlined by the WHO in its global health strategy on STIs [8].

Despite the crucial progress that has been made in terms of diagnosis, treatment and prevention (e.g. vaccination), STIs remain the most widespread and hazardous infectious diseases [9]. The WHO estimates that worldwide, about one million STIs are acquired every day [13]. Although a transient reduction in infection numbers was recorded in the late 1980s probably caused by changes in sexual behavior obeying to the nascent HIV pandemic - the incidence of STIs is back on the rise since the mid-1990s [14]. In Europe, for instance, the

doi: $10.15698 / \mathrm{mic} 2016.09 .522$

Received 22.08.2016, Accepted 30.08.2016, Published 05.09.2016

Keywords: STI, syphilis, gonorrhoea, chlamydia, trichomoniasis, hepatitis B, herpes simplex virus, human immunodeficiency virus, human papillomavirus, HPV, HBV, HIV. 
overall infection rates for gonorrhea have more than doubled between 2008 and 2014 [15] and in 2014, the recorded number of new HIV cases was the highest since reporting began in the 1980s [16]. There are many possible reasons for this increase in the occurrence of STIs. Although this might be partly due to the improved diagnostic capability following technical developments, recent changes in the demographic, social and economic status are thought to be determinant for this distressing trend. Among them, a lower rate of marriages concomitant with increasing numbers of lifetime sex partners, delayed childbirth and enhanced population movement (increased travel rates, international migration) represent only some factors that might influence transmission rates [5, 14]. In addition, at least for bacterial and protozoan STIs, antibiotic resistance is a growing phenomenon that undermines the available drug arsenal currently used to counteract the associated conditions [17]. Of note, the reported disease figures probably underrate the actual burden of infection, because of underreporting and the fact that a large number of STIs remain asymptomatic although they are infectious $[5,18]$. The resulting (unintentional) lack of awareness regarding the danger to transfer the pathogen and/or the smugness about the individual risk to acquire an STI also contributes to increased transmission [19].

So far, pathogen transmission via sexual contact is known for more than 30 different bacteria, viruses and parasites [13]. Thereof, three bacterial (syphilis, gonorrhea, chlamydia), a protozoan (trichomoniasis) and four viral (human papilloma virus (HPV), herpes simplex virus (HSV), hepatitis B virus (HBV), and HIV) STIs account for the majority of infection cases $[8$, 13]. In this Special Issue on STIs, Microbial Cell has compiled a series of articles that focus on these eight major STIs, covering

\section{REFERENCES}

1. Shafer WM and Ohneck EA (2011). Taking the Gonococcus-Human Relationship to a Whole New Level: Implications for the Coevolution of Microbes and Humans. mBio 2(3): e00067-11.

2. Baarda BI and Sikora AE (2015). Proteomics of Neisseria gonorrhoeae: the treasure hunt for countermeasures against an old disease. Front Microbiol: 6:1190.

3. Harper KN, Ocampo PS, Steiner BM, George RW, Silverman MS, Bolotin S, Pillay A, Saunders NJ, Armelagos GJ (2008). On the Origin of the Treponematoses: A Phylogenetic Approach. PLoS Negl. Trop Dis 2(1): e148.

4. Tampa M, Sarbu I, Matei C, Benea V, Georgescu SR (2015). Brief history of syphilis. J Med Life 7(1): 4-10. PMID: 24653750

5. O'Connor E, Lin JS, Burda BU, Henderson JT, Walsh ES, Whitlock EP (2014). Behavioral Sexual Risk Reduction Counseling in Primary Care to Prevent Sexually Transmitted Infections: An Updated Systematic Evidence Review for the U.S. Preventive Services Task Force. Ann Intern Med 161(12):874-83.

6. Center for Disease Control and Prevention (2014). Sexually transmitted disease surveillance 2013. Available at: http://www.cdc.gov/std/stats13/surv2013print.pdf [Accessed: 13.06.2016]

7. Glasier A, Gülmezoglu AM, Schmid GP, Garcia Moreno C, Van Look PFA (2006). Sexual and reproductive health: a matter of life and death. Lancet 368(9547): 1595-607.

8. World Health Organization (2015). Draft global health sector strategies: Sexually transmitted infections, 2016-2021. Available at: http://apps.who.int/gb/ebwha/pdf_files/EB138/B138_31-en.pdf [Accessed: 24.05.2016]

9. World Health Organization (2014). Report on global sexually transmitted infection surveillance $2013 . \quad$ Available at: http://apps.who.int/iris/bitstream/10665/112922/1/9789241507400_eng.pdf [Accessed: 24.05.2016]

10. Ward H, Rönn M (2010). Contribution of sexually transmitted infections to the sexual transmission of HIV. Curr Opin HIV AIDS 5(4):305-10. all relevant features of each infection: (i) etiology, transmission and protection; (ii) pathology/symptomatology; (iii) epidemiology, incidence and prevalence; (iv) treatment and curability; and (v) molecular mechanisms of infection. Therefore, this Special Issue attempts to provide a comprehensive overview for the specialized and general public, not least shedding light on STIs as the epidemic of colossal magnitude that it is.

\section{ACKNOWLEDGMENTS}

FM is grateful to the Austrian Science Fund FWF (Austria) for grants P23490-B12, P24381, P 27893, I1000 and grant 'SFB Lipotox' and to BMWFW and the Karl-Franzens University for grant 'Unkonventionelle Forschung' and grant DKplus Metabolic and Cardiovascular Diseases to KK and FM. We acknowledge support from NAWI Graz.

\section{CONFLICT OF INTEREST}

The authors declare no conflict of interest.

\section{COPYRIGHT}

(C) 2016 Carmona-Gutierrez et al. This is an open-access article released under the terms of the Creative Commons Attribution (CC BY) license, which allows the unrestricted use, distribution, and reproduction in any medium, provided the original author and source are acknowledged.

Please cite this article as: Didac Carmona-Gutierrez, Katharina Kainz and Frank Madeo (2016). Sexually transmitted infections: old foes on the rise. Microbial Cell 3(9): 361-362.

11. Wasserheit JN (1992). Epidemiological synergy. Interrelationships between human immunodeficiency virus infection and other sexually transmitted diseases. Sex Transm Dis 19(2):61-77. PMID: 1595015

12. Center for Disease Control and Prevention (2013). CDC Fact Sheet: Incidence, Prevalence, and Cost of Sexually Transmitted Infections in the United States. Available at: https://www.cdc.gov/std/stats/sti-estimates-fact-sheet-feb2013.pdf [Accessed: 14.07.2016].

13. World Health Organization (2015). Sexually Transmitted Infections (STIS) Available at: http://www.who.int/mediacentre/factsheets/fs110/en/ [Accessed 24.05.2016].

14. Fenton KA, Lowndes CM (2004). Recent trends in the epidemiology of sexually transmitted infections in the European Union. Sex Transm Infect 80:255263

15. European Center for Disease Prevention and Control (2016). Annual Epidemiological Report: Gonorrhoea. Available at: http://ecdc.europa.eu/en/healthtopics/gonorrhoea/Documents/AER2016/AERgonorrhoea.pdf [Accessed: 14.06.2016]

16. European Center for Disease Prevention and Control (2015). Highest number of new HIV cases in Europe ever. Available at: http://ecdc.europa.eu/en/press/Press\%20Releases/highest-number-new-HIVcases-ever-26-November-2015.pdf [Accessed: 14.06.2016]

17. Krupp K and Madhivanan P (2015). Antibiotic resistance in prevalent bacterial and protozoan sexually transmitted infections. Indian J Sex Transm Dis 36(1): 3-8.

18. Workowski KA and Berman SM (2011). Centers for Disease Control and Prevention Sexually Transmitted Disease Treatment Guidelines. Clin Infect Dis 53 (suppl 3): S59-S63.

19. Doherty L, A Fenton KA, Jones J, Paine TC, Higgins SP, Williams D, Palfreeman A (2002). Syphilis: old problem, new strategy. BMJ 325(7356):153-6. 